\title{
Hirschsprung’s Disease in Adult Treated by Coloprotectomy and Colo-Anal Anastomosis
}

\author{
Baraket O*, Karray O, Ayed K, Baccar A, Moussa M, Triki W and Bouchoucha S \\ Department of Surgery, Bizert Hospital, University Tunis El Manar, Tunisia
}

*Corresponding author: Baraket O, Department of Surgery, Bizert Hospital, University Tunis El Manar, Tunisia, E-mail: oubaraket@gmail.com

Citation: Baraket O, Karray O, Ayed K, Baccar A, Moussa M, et al. (2016) Hirschsprung's Disease in Adult Treated by Coloprotectomy and Colo-Anal Anastomosis. J Case Rep Stud 4(2): 210. doi: 10.15744/23489820.4.210

Received Date: January 09, 2016 Accepted Date: April 18, 2016 Published Date: April 20, 2016

\begin{abstract}
Hirschsprung's disease is a rare pathology Most cases become manifest during the neonatal period, but in rare instances, the disease is initially diagnosed in adult patients.

We report a case of the 26 years old man who presented a Hirschsprung disease. Developed severe intestinal obstruction and presented to the emergency department with significant abdominal distension. A computed tomographic scan confirmed significant fecal loading of the entire colon and rectum. The diagnosis was established through peroperatively biopsy. A rectal biopsy showing aganglionic anorectum. The treatment consist in a coloproctectomy with coloanal anastomosis.
\end{abstract}

The postoperative course was uneventful with complete resolution of the symptoms. Hirschsprung's disease should be considered in adults who have long-standing and refractory constipation.

Keywords: Hirschsprung's disease; Adult; Surgery

\section{Introduction}

Hirschsprung's disease or congenital aganglionic megacolon, occurs in approximately 1 in every 5000 live births and is about 4 times more frequent in males than in females. Hirschsprung disease is the most frequent aetiology of intestinal occlusion in child. This disease is characterized by lack of ganglionical cells in the submucous membrane and in the myenterical plexuses of the digestive tract in its distal part.

\section{Observation}

A 26-year-old man suffering from recurrent abdominal pain and constipation distention over a period of 6 years was admitted to our institution for increasing abdominal pain, distension, and symtoms of colonic obstruction by for a 4-day period for colonic obdtruction. He is complaining of many years of constipation. He underwent emergency laparotomy. The left colon and the rectum are markely dilated (Figure 1); a diverting loop colostomy was performed associated with a biopsy of the rectum and about $7 \mathrm{~kg}$ of feces was evacuated through the colostomy. Full-thickness rectal biopsies demonstrated a paucity of ganglion cells, suggestive of HD. colonoscopy, and laboratory studies were normal. After few weeks of examination, we found a significant abdominal distension and tympany to palpation. A plain $\mathrm{x}$ - ray film of the abdomen revealed extensive fecal retention throughout the colon. Computed tomographic scan in the axial plane through the abdomen confirmed the severe colonic dilatation along with extensive fecal loading and generalized colonic wall thickening (Figure 2). The rectum was markedly dilated and there was no obstructive lesion identified. Another rectal manometry that revealed a lack of anormal rectoanal inhibitory reflex. Sigmoidodcopy with biopsy of rectum and sigmoid colon showed no ganglion cells. Colonoscopy through the colstomy and biopsy was normal.

He underwent a total proctoctecomy with sigmoidectomy and colo-anal anastomosis between healthy colon and anal mucosa with diverting loop ileostomy. Histological staining revealed absence of ganglion cells in the myenteric plexus in the narrow segment consistent with the diagnosis of adult HD. The post operative course was infaithful. Her diverting ileostomy was taken down three months later. Actually two years after the intervention he has been well with complete resolution of symptoms and absolutely normal continence and sexual potency and good quality of life. 


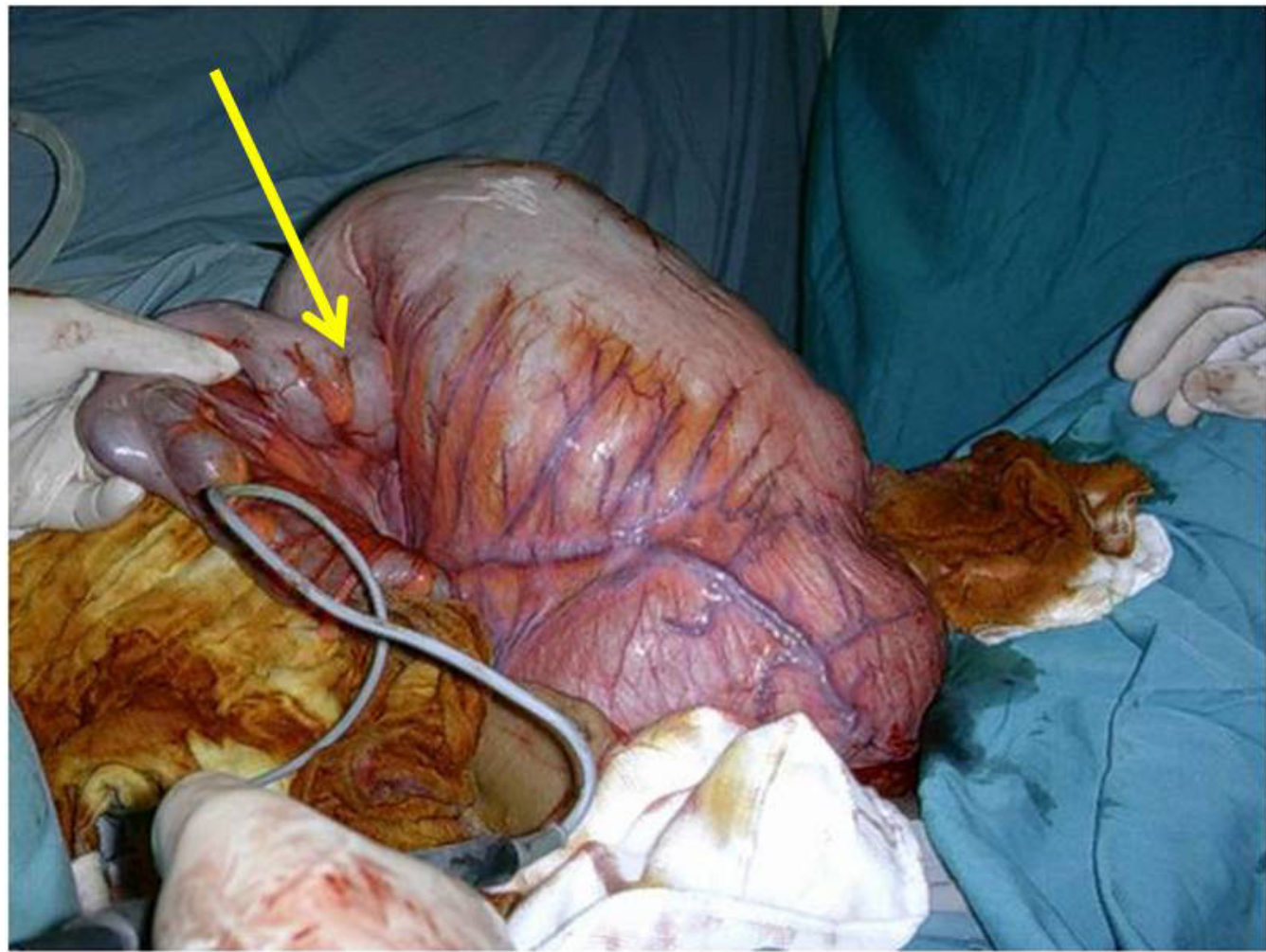

Figure 1: Per operatively view: The desending colon transverse and right colon is markely dilated and sigmoid rectum were narrow

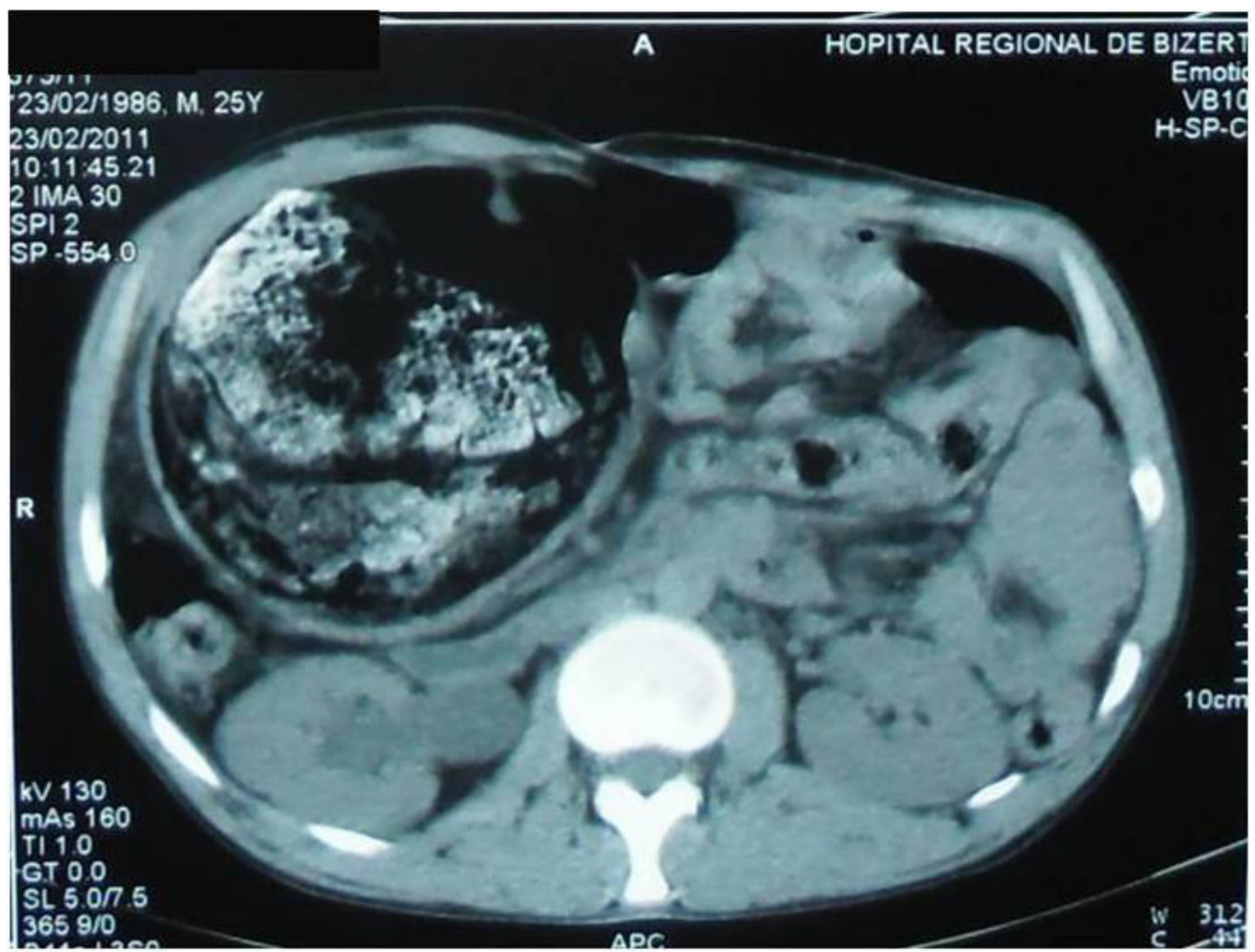

Figure 2: CT abdominal scan: severe colonic dilatation along with extensive fecal loading and generalized colonic wall thickening

\section{Discussion}

Congenital aganglionic megacolon was first described more than 100 years ago by Harald Hirschsprung, who published his classic description of the disease in 1888 [1]. The term badult HDQ has been arbitrarily applied by some investigators to cases in which the patient is older than 10 years when the diagnosis is established [2,3], whereas others have defined adult HD as cases in which 
the diagnosis was made after age 18 or 19 years [4]. Ninety-four percent of these cases are diagnosed before the patient is aged 5 years. In rare cases of these disorders, the patient may not receive a diagnosis until he or she reaches adulthood [5,6]. In our case the symtoms appears in adulthood. Nearly 300 cases with at least some features of adult or adolescent HD have been documented, some of which were diagnosed by rectal biopsy or resection. Fair grieve [2,7] documented HD in 7 men whose ages varied from 17 to 34 years.

The primary defect in adult HD is identical to that seen in infancy or childhood and is characterized by the total absence of intramural ganglion cells of the submucosal (Meissner) and myenteric (Auerbach) plexuses in the affected segment of the bowel.

The typical adult patient with HD has a history of longstandingconstipation since infancy or early childhood; the male to female ratio is approximately $4: 1$. Patient age ranges from 10 to 73 years, and the average age is 24.1 years. Half of the patients are younger than 30 years $[2-8,9]$. Other symptoms include abdominal discomfort, distension, and abdominal pain. Physical examination frequently reveals palpable fecal masses $[10,11]$.

The treatment of this affection is exclusively surgical. The surgical procedures developed to treat the disease in children have been applied to adults, Many procedures were reported in the littérature : Swenson abdominoperineal pull-through, Duhamel retrorectal pull-through, Soave endorectal pull-through, Lynn myectomy, LAR combined with myectomy, LAR with colectomy (State procedure). In our case we have use a coloprotectomy with a coloanal anastomosis [2,12-15].

The Duhamel procedure appeared to be associated with a lower rate of major postoperative complications than the other procedures, and the rate of good long-term results was higher [12]. Swenson [16] reported their collective results in 282 patients treated with the Swenson procedure, including 71 adults, and noted a 5\% incidence of anastomotic leak and $90 \%$ rate of excellent longterm results. Lynn procedure for posterior anorectal myectomy was advocated its usefulness as an initial approach or complementary procedure approach to short segment Hirschsprung's disease because of the low morbidity and absence of technical difficulty. The long-term results of a combination of anorectal myectomy and anterior resection showed excellent results with no major complications $[13,14,17,18]$.

All the procedures can now be performed laparoscopically and the results were excellents [13].

\section{Conclusion}

Hirshprung's disease is an uncommon cause of chronic constipation in adults, it should be considered in the differential diagnosis of this entity in similar clinical cases.

Surgical treatment is still the only curatif treatment of this disease. Results are excellents in most cases. The quality of life of the patients after surgery was excellent.

\section{References}

1. Hirschsprung H (1888) Stuhltragheit neugeborener in folge von dilatation und hypertrophie des colons. Jahrb Kinderheilkd 27: 1-7.

2. Chen F, Winston JH, Jain SK, Frankel WL (2006) Hirschsprung's disease in a young adult: report of a case and review of the literature. Ann Diagn Pathol 10: $347-51$.

3. Fishbein RH, Handelsman JC, Schuster MM (1986) Surgical treatment of Hirschsprung's disease in adults. Surg Gynecol Obset 163: 458-64.

4. Natsikas NB, Sbarounis CN (1987) Adult Hirschsprung's disease. An experience with the Duhamel-Martin procedure with special reference to obstructed patients. Dis Colon Rectum 30: 204-6.

5. Hamdy MH, Scobie WG (1984) Anorectal myectomy in adult Hirschsprung's disease: a report of six cases. Br J Surg 71: 611-3.

6. Bakari AA, Gali BM, Ibrahim AG, Nggada HA, Ali N, et al. (2011) Congenital aganglionic megacolon in Nigerian adults: two case reports and review of the literature. Niger J Clin Pract 14: 249-52.

7. Fortea-Sanchís C, Martínez-Ramos D, Rivadulla-Serrano I, Daroca-José JM, Paiva-Coronel G, et al. (2011) Hirschprung’s disease in adults. Rev Esp Enferm Dig 103: 150-1.

8. Miyamoto M, Egami K, Maeda S, Ohkawa K, Tanaka N, et al. (2005) Hirschsprung's disease in adults: report of a case and review of the literature. J Nippon Med Sch 72: 113-20.

9. Tsimmerman IaS (2011) Hirschsprung's disease in adults. Klin Med (Mosk) 89: 60-3.

10. Rintala RJ, Pakarinen MP (2012) Long-term outcomes of Hirschsprung's disease. Semin Pediatr Surg 21: 336-43.

11. Alagumuthu M, Jagdish S, Kadambari D (2011) Hirschsprung's disease in adults presenting as sigmoid volvulus: a report of three cases. Trop Gastroenterol 32: $341-3$.

12. Adhi M, Khan S, Zafar H, Arshad M (2012) Duhamel's procedure for adult Hirschsprung's disease. J Coll Physicians Surg Pak 22: 395-7.

13. Ammar SA, Ibrahim IA (2011) One-stage transanal endorectal pull-through for treatment of hirschsprung's disease in adolescents and adults. J Gastrointest Surg 15: 2246-50.

14. Jarry J, Faucheron JL (2011) Laparoscopic rectosigmoid resection with transanal colonic pull-through and delayed coloanal anastomosis: a new approach to adult Hirschsprung disease. Dis Colon Rectum 54: 1313-9.

15. Ieiri S, Nakatsuji T, Akiyoshi J, Higashi M, Hashizume M, et al. (2010) Long-term outcomes and the quality of life of Hirschsprung disease in adolescents who have reached 18 years or older--a 47-year single-institute experience. J Pediatr Surg 45: 2398-402.

16. Jarvi K, Laitakari EM, Koivusalo A, Rintala RJ, Pakarinen MP (2010) Bowel function and gastrointestinal quality of life among adults operated for Hirschsprung diseaseduring childhood: a population-based study. Ann Surg 252: 977-81. 
17. Swenson O, Sherman JO, Fisher JH, Cohen E (1975) The treatment and postoperative complications of congenital megacolon. A 25 year follow up. Ann Surg 182: 266-73.

18. Pattana-arun J, Ruanroadroun T, Tantiphalachiva K, Sahakitrungruang C, Attithansakul P, et al. (2010) Internal sphincter myectomy for adult Hirschsprung's disease: a single institute experience. J Med Assoc Thai 93: 911-5.

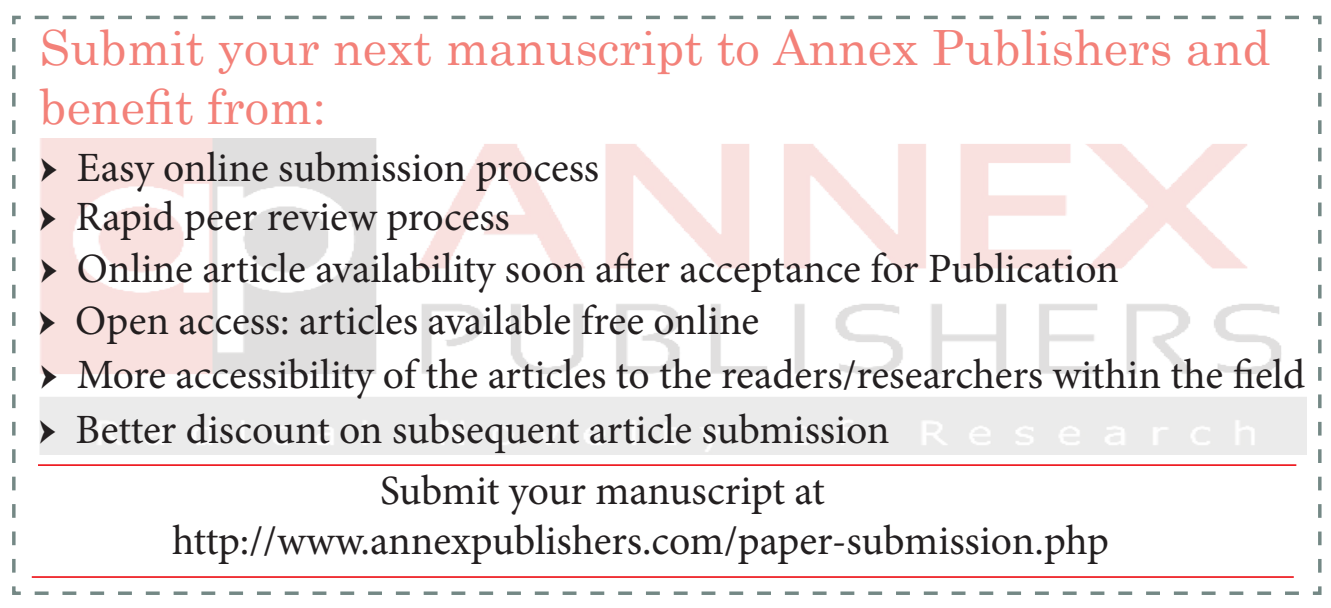

